\title{
PENGEMBANGAN PERANGKAT PEMBELAJARAN IPA BERBASIS INKUIRI TERBIMBING DENGAN TUGAS PROYEK MATERI SISTEM EKSKRESI UNTUK MENUNTASKAN HASIL BELAJAR SISWA SMP
}

\author{
Baharuddin \\ Program Pascasarjana Pendidikan Sains UNESA Surabaya \\ E-mail: udhinbahar83@gmail.com
}

\begin{abstract}
Abstrak: Pendidikan adalah usaha sadar yang dilakukan oleh pendidik dalam membelajarkan peserta didik agar lebih baik. Ada banyak hal yang bisa dilakukan oleh seorang pendidik, salah satunya adalah dengan mengembangkan perangkat pembelajaran yang berorientasi kepada kepentingan siswa dengan harapan agar hasil belajar siswa dapat meningkat. Berdasarkan hasil yang diperoleh, dapat disimpulkan bahwa perangkat pembelajaran IPA berbasis inkuiri terbimbing dengan tugas proyek yang telah dikembangkan efektif untuk menuntaskan hasil belajar siswa SMP
\end{abstract}

Kata Kunci: Tugas Proyek, Sistem Ekskresi, Hasil Belajar

\section{DEVELOPMENT OF A DEVICE BASED SCIENCE LEARNING INQUARY INSTRUCTION MATERIAL THE EXCRETORY SYSTEM PROJECT TO FINISH THE STUDY RESULTS JUNIOR HIGH SCHOOL STUDENTS}

\begin{abstract}
: education is a conscious effort done by educator in membelajarkan students have a better. There a lot that could be undertaken by an educator, one example is the develop a device of learning which he oriented to the interests of students in the hope of it is aimed the result of students to study can increase. Based on the results obtained, it can be concluded that a device learning ipa based inkuiri terbimbing with the duty of projects that have developed effective to complete the negotiations on learning outcomes junior high school students
\end{abstract}

Keywords: The Project, The System Excretion, Study Results

Pendidikan IPA juga diarahkan untuk proses inkuiri dan berbuat, sehingga dapat membantu siswa untuk memperoleh pemahaman yang lebih mendalam tentang alam sekitar (Mulyasa, 2013). Pembelajaran inkuiri memungkinkan siswa untuk dapat menjawab masalah-masalah dan mencari penjelasan-penjelasan yang memungkinkan untuk menyelesaikan masalah tersebut. Inkuiri dapat dipandang sebagai suatu proses untuk menjawab pertanyaan dan memecahkan masalah berdasarkan fakta dan observasi. 
Pembelajaran Inkuiri membimbing siswa bagaimana meneliti masalah dan pertanyaan berdasarkan fakta, melibatkan siswa dalam kegiatan inkuri merupakan salah satu cara yang efektif untuk membantu siswa memahami struktur atau ide kunci dari suatu disiplin ilmu (Kardi, 2013).

Berdasarkan hasil survei yang dilaksanakan di SMP Negeri 16 Poleang Tengah, pembelajaran IPA pada kenyataannya tidak memfasilitasi siswa untuk aktif membangun pengetahuannya sendiri. Siswa hanya duduk mendengarkan guru, mencatat dan mengerjakan latihan. Proses pembelajaran hanya sebatas pada konsep-konsep yang tertuang dalam buku pelajaran, tanpa ada upaya untuk menerapkan konsep-konsep tersebut dalam kehidupan sehari-hari. Siswa lebih dituntut untuk menghafal pelajaran, tanpa diminta untuk memahami dan mengaplikasikan pengetahuan tersebut dalam kehidupan sehari-hari sehingga kemampuan sikap, pengetahuan dan keterampilan tidak dapat tumbuh dan berkembang dengan baik. Siswa hanya mampu menjawab pertanyaan tanpa tahu bagaimana menerapkan konsep-konsep dan prinsip-prinsip tersebut dalam kehidupan sehari-hari.

Sistem pembelajaran yang cenderung monoton, tidak bervariasi dan kurangnya upaya guru untuk mengaplikasikan konsep dan prinsip yang diterima siswa, menjadikan mata pelajaran IPA menjadi mata pelajaran yang membosankan dan sulit untuk dipahami. Fakta ini terlihat dari rendahnya persentase ketuntasan hasil belajar siswa kelas VIII tahun pelajaran 2014/2015 pada semester ganjil. Ketuntasan hasil belajar siswa kelas VIII tahun pelajaran 2014/2015 semester ganjil SMP Negeri 16 Poleang Tengah pada mata pelajaran IPA hanya mencapai $42 \%$ sedangkan $58 \%$ siswa dinyatakan tidak tuntas. Hasil wawancara dari beberapa siswa kelas VIII, menunjukkan bahwa mata pelajaran IPA kurang menarik bagi para siswa. Pelajaran IPA merupakan pelajaran yang membosankan karena guru hanya memberi informasi kepada siswa dan kemudian memberi beban kepada siswa dengan hafalan materi yang sangat banyak. Pengetahuan yang diperoleh siswa hanya sebatas pengetahuan konseptual, sehingga pembelajaran menjadi tidak bermakna.

Model pembelajaran yang dapat memberikan kesempatan bagi siswa untuk mendapatkan pemahaman tentang metode ilmiah guna mengembangkan kemampuan berpikir, pengaturan diri dan pemahaman tentang topik-topik spesifik adalah model pembelajaran inkuiri. Pembelajaran inkuiri adalah model pembelajaran yang dirancang untuk memberi siswa pengalaman metode ilmiah. Metode ilmiah adalah pola pemikiran yang menekankan pada pengajuan pertanyaan, mengembangkan hipotesis untuk menjawab pertanyaan-pertanyaan dan menguji hipotesis dengan data (Eggen dan Kauchak, 2012). Proses inkuiri merupakan kegiatan menjawab permasalahan dengan cara membuat prediksi dan mengujinya dengan data sehingga siswa mendapatkan pengalaman memecahkan masalah dan melakukan penyelidikan. Proses mengumpulkan data dan 
analisis hipotesis yang rumit memerlukan bimbingan guru untuk membantu siswa melalui proses inkuiri terbimbing (Banchi, 2008).

\section{METODE PENELITIAN}

Penelitian ini merupakan pengembangan dan penerapan perangkat pembelajaran berbasis inkuiri terbimbing dengan tugas proyek pada materi sistem ekskresi untuk ketuntasan hasil belajar siswa SMP. Perangkat pembelajaran yang dikembangkan menggunakan kurikulum 2013 meliputi: 1) Rencana Pelaksanaan Pembelajaran (RPP); 2) Lembar Kegiatan Siswa (LKS); 3) Buku Ajar Siswa (BAS); dan 4) Instrumen penilaian hasil belajar yang terdiri dari: instrumen penilaian sikap, instrumen penilaian hasil belajar aspek pengetahuan, dan instrumen penilaian hasil belajar siswa pada aspek keterampilan dalam hal ini tugas proyek. Proses pengembangan perangkat pembelajaran mengacu pada model pengembangan Dick \& Carey (2009). Pemilihan model pengembangan perangkat dengan model Dick \& Carey dikarenakan memiliki tahapan-tahapan yang lebih terperinci dan sistematis, ini terlihat dari masing-masing tahap yang harus dilakukan pada penyusunan perencanaan proses pembelajaran.

\section{HASIL DAN PEMBAHASAN}

\section{Rencana Pelaksanaan Pembelajaran (RPP)}

Validator memvalidasi RPP dengan hasil rata-rata untuk aspek format 3,50 dengan kategori valid, aspek isi 3,76 dengan kategori sangat valid, dan aspek bahasa 3,33 dengan kategori valid (Ratumanan \& Laurens, 2011) dengan rata-rata percentage of agreement antar tiga validator sebesar $86,24 \%$, maka hasil penilaian tiga validator dinyatakan sangat baik dan cocok karena memperoleh nilai $\geq 75 \%$ (Borich, 1994). Hasil tersebut menunjukkan bahwa RPP yang dikembangkan secara umum masuk kategori valid dan layak digunakan dalam pembelajaran setelah melalui tahap revisi sesuai saran dari validator ahli. Revisi tersebut meliputi perbaikan beberapa kata dalam RPP yang kurang sesuai dengan ejaan Bahasa Indonesia yang baik dan benar serta perbaikan beberapa kata dalam indikator dan tujuan pembelajaran. Hasil analisis data validasi RPP disajikan pada Tabel 1 sebagai berikut:

Tabel 1. Hasil Validasi Rencana Pelaksanaan Pembelajaran

\begin{tabular}{|c|c|c|c|c|c|c|c|c|}
\hline \multirow{2}{*}{ No } & \multirow{2}{*}{\multicolumn{2}{|c|}{ Aspek yang Dinilai }} & \multicolumn{3}{|c|}{ Penilaian } & \multirow{2}{*}{ Rerata } & \multirow{2}{*}{$\mathbf{K}$} & \multirow{2}{*}{$\begin{array}{c}\text { POA } \\
(\%)\end{array}$} \\
\hline & & & V1 & V2 & V3 & & & \\
\hline \multirow[t]{6}{*}{ I } & \multicolumn{8}{|c|}{ FORMAT } \\
\hline & 1 & $\begin{array}{l}\text { Pembagian materi sesuai alokasi } \\
\text { waktu }\end{array}$ & 4 & 4 & 4 & 4,00 & SV & 100,00 \\
\hline & 2 & Sistem penomoran & 3 & 3 & 3 & 3,00 & $\mathrm{~V}$ & 100,00 \\
\hline & 3 & Pengaturan ruang/tata letak & 3 & 3 & 3 & 3,00 & $\mathrm{~V}$ & 100,00 \\
\hline & 4 & Jenis dan ukuran huruf sesuai & 4 & 4 & 4 & 4,00 & SV & 100,00 \\
\hline & \multicolumn{5}{|c|}{ Rata-Rata } & $3, \mathbf{5 0}$ & $\mathbf{V}$ & $\mathbf{1 0 0 , 0 0}$ \\
\hline
\end{tabular}




\begin{tabular}{|c|c|c|c|c|c|c|c|c|}
\hline \multirow[t]{9}{*}{ II } & \multicolumn{8}{|c|}{ ISI } \\
\hline & 1 & Menuliskan kompetensi dasar & 4 & 4 & 4 & 4,00 & SV & 100,00 \\
\hline & 2 & Menuliskan indicator & 4 & 3 & 4 & 3,67 & SV & 66,67 \\
\hline & 3 & $\begin{array}{l}\text { Ketepatan antara indikator dengan } \\
\text { KD }\end{array}$ & 4 & 3 & 4 & 3,67 & SV & 66,67 \\
\hline & 4 & Kesesuaian dengan kurikulum & 4 & 4 & 4 & 4,00 & SV & 100,00 \\
\hline & 5 & $\begin{array}{l}\text { Pemilihan model, metode, dan } \\
\text { sarana pembelajaran dilakukan } \\
\text { dengan tepat, } \\
\text { memungkinkan siswa aktif dalam } \\
\text { kegiatan pembelajaran }\end{array}$ & 4 & 3 & 4 & 3,67 & SV & 66,67 \\
\hline & 6 & $\begin{array}{l}\text { Fase-fase model dituliskan secara } \\
\text { jelas sehingga mudah dilaksanakan } \\
\text { dalam proses pembelajaran }\end{array}$ & 4 & 4 & 4 & 4,00 & SV & 100,00 \\
\hline & 7 & $\begin{array}{l}\text { Kesesuaian alokasi waktu yang } \\
\text { digunakan }\end{array}$ & 3 & 3 & 4 & 3,33 & V & 66,67 \\
\hline & \multicolumn{5}{|c|}{ Rata-Rata } & 3,76 & SV & $\mathbf{8 0 , 9 5}$ \\
\hline \multirow[t]{5}{*}{ III } & \multicolumn{8}{|c|}{ BAHASA } \\
\hline & 1 & $\begin{array}{l}\text { Kebenaran tata bahasa Indonesia } \\
\text { yang baik dan benar }\end{array}$ & 3 & 3 & 4 & 3,33 & $\mathrm{~V}$ & 66,67 \\
\hline & 2 & Ketepatan struktur kalimat & 3 & 3 & 3 & 3,00 & $\mathrm{~V}$ & 100,00 \\
\hline & 3 & $\begin{array}{l}\text { Bahasa yang dipergunakan bersifat } \\
\text { komunikatif }\end{array}$ & 4 & 3 & 4 & 3,67 & SV & 66,67 \\
\hline & \multicolumn{5}{|c|}{ Rata-Rata } & 3,33 & $\mathbf{V}$ & 77,78 \\
\hline \multicolumn{3}{|c|}{ Rata-rata Semua Aspek } & \multicolumn{6}{|c|}{$\mathbf{3 , 5 3}$} \\
\hline \multicolumn{3}{|c|}{ Rata-rata percentage of agreement } & \multicolumn{6}{|c|}{86,24} \\
\hline \multicolumn{3}{|c|}{ Kategori RPP yang dikembangkan } & \multicolumn{6}{|c|}{ Valid } \\
\hline
\end{tabular}

\section{Keterangan:}

$\mathrm{V}_{1} \quad$ : Validator 1

$\mathrm{V}_{2} \quad$ : Validator 2

V : Valid

$\mathrm{V}_{3} \quad$ : Validator 3

POA : Percentage of agreement

SV : Sangat Valid

K : Kategori

\section{Lembar Kerja Siswa (LKS)}

Rata-rata hasil validasi terhadap Lembar Kerja Siswa (LKS) dari tiga validator ahli pada aspek format sebesar 3,33 dengan kategori valid, aspek isi sebesar 3,27 dengan kategori valid, dan aspek bahasa sebesar 3,67 dengan kategori sangat valid (Ratumanan \& Laurens, 2011). Rata-rata percentage of agreement antar tiga validator sebesar 78,52 $\%$, maka hasil penilaian tiga validator dinyatakan sangat baik dan cocok karena memperoleh nilai $\geq 75 \%$ (Borich, 1994). Hasil tersebut secara umum menunjukkan bahwa LKS yang telah dikembangkan valid dan layak digunakan dalam pembelajaran setelah direvisi sesuai dengan saran dari validator ahli. Revisi yang disarankan oleh validator meliputi perbaikan penulisan beberapa kalimat yang perlu disesuaikan lagi 
dengan ejaan yang baik dan benar, perbaikan terhadap gambar pendukung yang dirasa kurang jelas, dan beberapa kalimat pertanyaan yang perlu disesuaikan dengan tingkat pemahaman siswa. Analisis data hasil validasi LKS disajikan pada Tabel 2 sebagai berikut:

Tabel 2. Hasil Validasi Lembar Kegiatan Siswa

\begin{tabular}{|c|c|c|c|c|c|c|c|c|}
\hline \multirow{2}{*}{ No } & \multirow{2}{*}{\multicolumn{2}{|c|}{ Aspek yang Dinilai }} & \multicolumn{3}{|c|}{ Penilaian } & \multirow{2}{*}{ Rerata } & \multirow{2}{*}{$\mathbf{K}$} & \multirow{2}{*}{$\begin{array}{c}\text { POA } \\
(\%)\end{array}$} \\
\hline & & & V1 & V2 & V3 & & & \\
\hline \multirow[t]{6}{*}{ I } & \multicolumn{8}{|c|}{ FORMAT } \\
\hline & 1 & $\begin{array}{l}\text { Pembagian materi sesuai alokasi } \\
\text { waktu }\end{array}$ & 4 & 3 & 4 & 3,67 & SV & 66,67 \\
\hline & 2 & Sistem penomoran & 3 & 3 & 3 & 3,00 & $\mathrm{~V}$ & 100,00 \\
\hline & 3 & Pengaturan ruang/tata letak & 4 & 3 & 4 & 3,67 & SV & 66,67 \\
\hline & 4 & Jenis dan ukuran huruf sesuai & 3 & 3 & 3 & 3,00 & $\mathrm{~V}$ & 100,00 \\
\hline & \multicolumn{5}{|c|}{ Rata-Rata } & 3,33 & $\mathbf{V}$ & 83,33 \\
\hline \multirow[t]{7}{*}{ II } & \multicolumn{8}{|c|}{ ISI } \\
\hline & 1 & Kebenaran isi/ materi. & 3 & 3 & 3 & 3,00 & $\mathrm{~V}$ & 100,00 \\
\hline & 2 & Merupakan materi yang esensial & 3 & 3 & 3 & 3,00 & $\mathrm{~V}$ & 100,00 \\
\hline & 3 & $\begin{array}{l}\text { Dikelompokkan dalam bagian- } \\
\text { bagian yang logis. }\end{array}$ & 4 & 3 & 4 & 3,67 & SV & 66,67 \\
\hline & 4 & $\begin{array}{l}\text { Kesesuaian dengan pembelajaran } \\
\text { yang berorientasi pada siswa aktif. }\end{array}$ & 4 & 2 & 4 & 3,33 & V & 66,67 \\
\hline & 5 & $\begin{array}{l}\text { Kesesuian dengan model inkuiri } \\
\text { terbimbing }\end{array}$ & 4 & 2 & 4 & 3,33 & $\mathrm{~V}$ & 66,67 \\
\hline & \multicolumn{5}{|c|}{ Rata-Rata } & 3,27 & $\mathbf{V}$ & 80,00 \\
\hline \multirow[t]{8}{*}{ III } & \multicolumn{8}{|c|}{ BAHASA } \\
\hline & 1 & Kebenaran tata bahasa. & 4 & 3 & 4 & 3,67 & SV & 66,67 \\
\hline & 2 & $\begin{array}{l}\text { Kesesuaian kalimat dengan taraf } \\
\text { berpikir dan kemampuan membaca } \\
\text { serta usia siswa. }\end{array}$ & 3 & 3 & 4 & 3,33 & $\mathrm{~V}$ & 66,67 \\
\hline & 3 & Kesederhanaan struktur kalimat. & 4 & 3 & 4 & 3,67 & SV & 66,67 \\
\hline & 4 & $\begin{array}{l}\text { Kalimat tidak mengandung arti } \\
\text { ganda. }\end{array}$ & 4 & 3 & 4 & 3,67 & SV & 66,67 \\
\hline & 5 & Kejelasan petunjuk dan arahan & 4 & 3 & 4 & 3,67 & SV & 66,67 \\
\hline & 6 & $\begin{array}{l}\text { Bahasa yang dipergunakan bersifat } \\
\text { komunikatif }\end{array}$ & 4 & 4 & 4 & 4,00 & SV & 100,00 \\
\hline & & Rata-Rata & & & & 3,67 & SV & 72,22 \\
\hline \multicolumn{3}{|c|}{ Rata-rata Semua Aspek } & \multicolumn{6}{|c|}{3,42} \\
\hline \multicolumn{3}{|c|}{ Rata-rata percentage of agreement } & \multicolumn{6}{|c|}{78,52} \\
\hline \multicolumn{3}{|c|}{ Kategori LKS yang dikembangkan } & \multicolumn{6}{|c|}{ Valid } \\
\hline
\end{tabular}

Keterangan:

$\begin{array}{llll}\mathrm{V}_{1} & \text { : Validator } 1 & \mathrm{~V} & \text { : Valid } \\ \mathrm{V}_{2} & \text { : Validator } 2 & \mathrm{SV} & \text { : Sangat Valid }\end{array}$




\section{$\mathrm{V}_{3} \quad$ : Validator 3 \\ POA : Percentage of agreement}

K : Kategori

\section{Buku Ajar Siswa (BAS)}

Buku Ajar Siswa (BAS) yang dikembangkan kemudian divalidasi sehingga diperoleh rata-rata hasil validasi dari tiga validator pada aspek format sebesar 3,27 dengan kategori valid, aspek isi/ penyajian materi sebesar 3,24 dengan kategori valid, aspek bahasa sebesar 3,33 dengan kategori valid, dan aspek fisik sebesar 3,00 dengan kategori valid (Ratumanan \& Laurens, 2011). Rata-rata percentage of agreement antar tiga validator sebesar 79,46\%, maka hasil penilaian tiga validator dinyatakan sangat baik dan cocok karena memperoleh nilai $\geq 75 \%$ (Borich, 1994). Hasil tersebut menunjukkan bahwa buku ajar siswa yang telah dikembangkan valid dan layak untuk dijadikan panduan siswa dalam proses pembelajaran setelah direvisi sesuai dengan saran validator ahli. Revisi yang disarankan meliputi perbaikan penulisan kalimat yang kurang sesuai dengan ejaan yang disempurnakan (EYD), perbaikan urutan materi yang dituliskan, penambahan materi yang dirasa perlu dituliskan, serta perbaikan beberapa gambar dalam BAS. Analisis data hasil validasi buku ajar siswa secara ringkas disajikan pada Tabel 4.3 sebagai berikut.

Tabel 3. Hasil Validasi Buku Ajar Siswa

\begin{tabular}{|c|c|c|c|c|c|c|c|c|}
\hline \multirow{2}{*}{$\begin{array}{l}\mathbf{N} \\
\mathbf{0}\end{array}$} & \multirow{2}{*}{\multicolumn{2}{|c|}{ Aspek yang Dinilai }} & \multicolumn{3}{|c|}{ Penilaian } & \multirow{2}{*}{ Rerata } & \multirow{2}{*}{$\mathbf{K}$} & \multirow{2}{*}{$\begin{array}{c}\text { POA } \\
(\%)\end{array}$} \\
\hline & & & V1 & $\mathbf{V 2}$ & V3 & & & \\
\hline \multirow[t]{7}{*}{ I } & \multicolumn{8}{|c|}{ ISI / MATERI } \\
\hline & 1 & Kesesuaian materi dengan kurikulum & 4 & 3 & 4 & 3,67 & SV & 66,67 \\
\hline & 2 & Keluasan/cakupan materi & 3 & 2 & 3 & 2,67 & $\mathrm{~V}$ & 66,67 \\
\hline & 3 & Tingkat kesulitan materi & 4 & 3 & 4 & 3,67 & SV & 66,67 \\
\hline & 4 & $\begin{array}{l}\text { Kesesuaian materi dengan } \\
\text { perkembangan ilmu pengetahuan dan } \\
\text { teknologi }\end{array}$ & 3 & 2 & 3 & 2,67 & $\mathrm{~V}$ & 66,67 \\
\hline & 5 & Kebenaran konsep dalam materi & 4 & 3 & 4 & 3,67 & SV & 66,67 \\
\hline & & Rata-Rata & & & & 3,27 & $\mathbf{V}$ & 66,67 \\
\hline \multirow[t]{7}{*}{ II } & \multicolumn{8}{|c|}{ PENYAJIAN MATERI } \\
\hline & 1 & $\begin{array}{l}\text { Ketepatan penggunaan konsep dalam } \\
\text { sajian materi }\end{array}$ & 3 & 2 & 3 & 2,67 & $\mathrm{~V}$ & 66,67 \\
\hline & 2 & $\begin{array}{l}\text { Motivasi yang mendorong siswa } \\
\text { untuk belajar }\end{array}$ & 3 & 3 & 3 & 3,00 & $\mathrm{~V}$ & 100,00 \\
\hline & 3 & $\begin{array}{l}\text { Kekonsistensian penggunaan konsep } \\
\text { dalam sajian materi }\end{array}$ & 4 & 3 & 4 & 3,67 & SV & 66,67 \\
\hline & 4 & $\begin{array}{l}\text { Memberikan ringkasan atau } \\
\text { rangkuman materi di bagian akhir }\end{array}$ & 4 & 3 & 4 & 3,67 & SV & 66,67 \\
\hline & 5 & $\begin{array}{l}\text { Keterhubungan materi dengan } \\
\text { lingkungan sekitar siswa }\end{array}$ & 3 & 3 & 3 & 3,00 & V & 100,00 \\
\hline & 6 & $\begin{array}{l}\text { Kesesuaian penyajian materi dengan } \\
\text { tingkat berpikir siswa }\end{array}$ & 3 & 3 & 4 & 3,33 & $\mathrm{~V}$ & 66,67 \\
\hline
\end{tabular}




\begin{tabular}{|c|c|c|c|c|c|c|c|c|}
\hline & 7 & Urutan sajian materi & 3 & 3 & 4 & 3,33 & $\mathrm{~V}$ & 66,67 \\
\hline & 8 & $\begin{array}{l}\text { Ketepatan sajian materi dalam } \\
\text { menciptakan siswa aktif belajar }\end{array}$ & 3 & 3 & 4 & 3,33 & $\mathrm{~V}$ & 66,67 \\
\hline & 9 & $\begin{array}{l}\text { Ketepatan sajian materi dalam } \\
\text { menciptakan kerja sama antar sesama } \\
\text { siswa dan antara siswa dengan guru }\end{array}$ & 3 & 3 & 3 & 3,00 & $\mathrm{~V}$ & 100,00 \\
\hline & 10 & $\begin{array}{l}\text { Kemenarikan sajian materi } \\
\text { (penggunaan ilustrasi, gambar warna- } \\
\text { warni dan tulisan yang dapat menarik } \\
\text { perhatian siswa) }\end{array}$ & 3 & 2 & 3 & 2,67 & $\mathrm{~V}$ & 66,67 \\
\hline & 11 & Identitas tabel dan gambar & 4 & 3 & 3 & 3,33 & $\mathrm{~V}$ & 66,67 \\
\hline & 12 & Kesesuaian ilustrasi dengan materi & 3 & 3 & 3 & 3,00 & $\mathrm{~V}$ & 100,00 \\
\hline & 13 & $\begin{array}{l}\text { Evaluasi yang memberi kesempatan } \\
\text { kepada siswa untuk menggali tingkat } \\
\text { pemahamannya terhadap konsep }\end{array}$ & 4 & 3 & 4 & 3,67 & SV & 66,67 \\
\hline & 14 & $\begin{array}{l}\text { Daftar rujukan (pustaka) yang } \\
\text { Digunakan }\end{array}$ & 4 & 3 & 4 & 3,67 & SV & 66,67 \\
\hline & \multicolumn{5}{|c|}{ Rata-Rata } & 3,24 & $\mathbf{V}$ & 76,19 \\
\hline \multirow[t]{6}{*}{ III } & \multicolumn{8}{|c|}{ BAHASA } \\
\hline & 1 & $\begin{array}{l}\text { Ketepatan penggunaan Bahasa } \\
\text { Indonesia }\end{array}$ & 3 & 3 & 4 & 3,33 & $\mathrm{~V}$ & 66,67 \\
\hline & 2 & Keterbacaan bahasa & 3 & 3 & 4 & 3,33 & $\mathrm{~V}$ & 66,67 \\
\hline & 3 & $\begin{array}{l}\text { Ketepatan penggunaan istilah/kata } \\
\text { dan simbol/lambing }\end{array}$ & 3 & 3 & 3 & 3,00 & SV & 100,00 \\
\hline & 4 & $\begin{array}{l}\text { Kesesuaian tingkat kesulitan bahasa } \\
\text { dengan tingkat berpikir siswa }\end{array}$ & 4 & 3 & 4 & 3,67 & SV & 66,67 \\
\hline & & Rata-Rata & & & & 3,33 & $\mathbf{V}$ & 75,00 \\
\hline \multirow[t]{5}{*}{ IV } & \multicolumn{8}{|c|}{ FISIK } \\
\hline & 1 & Kejelasan cetakan & 3 & 3 & 3 & 3,00 & $\mathrm{~V}$ & 100,00 \\
\hline & 2 & Ketepatan gambar dengan materi & 3 & 3 & 3 & 3,00 & $\mathrm{~V}$ & 100,00 \\
\hline & 3 & Cetakan huruf & 3 & 3 & 3 & 3,00 & $\mathrm{~V}$ & 100,00 \\
\hline & & Rata-Rata & & & & 3,00 & $\mathbf{V}$ & 100,00 \\
\hline \multicolumn{3}{|c|}{ Rata-rata Semua Aspek } & \multicolumn{6}{|c|}{3,21} \\
\hline \multicolumn{3}{|c|}{ Rata-rata percentage of agreement } & \multicolumn{6}{|c|}{79,46} \\
\hline \multicolumn{3}{|c|}{ Kategori BAS yang dikembangkan } & \multicolumn{6}{|c|}{ Valid } \\
\hline \multicolumn{9}{|c|}{ Kesimpulan: } \\
\hline
\end{tabular}

\section{Keterangan:}

$\mathrm{V}_{1} \quad$ : Validator 1

$\mathrm{V}_{2} \quad$ : Validator 2

$\mathrm{V} \quad$ : Valid

$\mathrm{V}_{3} \quad$ : Validator 3

SV : Sangat Valid

POA : Percentage of agreement

K : Kategori 
1. Perangkat pembelajaran IPA berbasis inkuiri terbimbing dengan tugas proyek untuk menuntaskan hasil belajar siswa yang telah dikembangkan dinyatakan valid dan dapat digunakan dalam kegiatan pembelajaran IPA di SMP.

2. Kepraktisan perangkat pembelajaran IPA yang dikembangkan melalui implementasi pada uji coba II dilihat dari:

a. Persentase keterlaksanaan seluruh tahapan pembelajaran pada RPP 1 dan RPP 2 masing-masing sebesar 95\%, RPP 3 dan RPP 4 masing-masing sebesar 100\% dengan kategori terlaksana sangat baik, sedangkan rata-rata skor pada tiap tahapan pembelajaran masuk dalam kategori baik.

b. Hasil pengamatan aktivitas siswa pada uji coba II diketahui bahwa persentase aktivitas yang dominan selama tiga kali pertemuan adalah aktivitas yang melibatkan siswa aktif dalam pembelajaran seperti menjawab pertanyaan dan menyampaikan pendapat, menganalisis data, dan melaksanakan kegiatan pengumpulan data. Aktivitas minta bimbingan kepada guru dan tindakan yang tidak relevan mengalami penurunan di setiap pertemuaan. Berdasarkan hasil di atas dapat disimpulkan bahwa perangkat pembelajaran IPA berbasis inkuiri terbimbing dengan tugas proyek yang telah dikembangkan praktis dilaksanakan dalam pembelajaran untuk menuntaskan hasil belajar siswa.

c. Kendala yang dihadapi pada saat uji coba satu antara lain terkait masalah menejemen waktu, namun hal ini dapat diperbaiki pada pertemuan kedua ketiga dan keempat, sehingga secara umum pembelajaran pada uji coba II berjalan dengan baik. Kemudian siswa kurang aktif membaca buku dan LKS, dan diberikan solusi Guru harus sering mengingatkan untuk membaca BAS yang dapat mendukung dalam menyelesaikan masalah dalam LKS. Kurangnya fasilitas sarana dan alat-alat di sekolah namun diberikan alternatif lain dengan mencari media, sarana atau alaalat percobaan yang sesuai dengan pengembangan perangkat yang telah disusun.

3. Keefektifan perangkat pembelajaran melalui implementasi pada uji coba II dilihat dari:

a. Penerapan perangkat pembelajaran IPA berbasis inkuiri terbimbing dengan tugas proyek dapat menuntaskan hasil belajar siswa pada aspek pengetahuan. Peningkatan hasil belajar aspek pengetahuan dapat dilihat dari $\mathrm{N}$-gain yaitu 0,79 dengan kategori tinggi.

b. Penerapan perangkat pembelajaran IPA berbasis inkuiri terbimbing dengan tugas proyek dapat mengembangkan aspek sikap siswa baik sikap spiritual maupun aspek sosial dengan kategori sangat baik dan baik.

c. Kesuluruhan siswa dinyatakan tuntas dalam tugas proyek dengan rata-rata nilai 86 dengan predikat A (Sangat Baik).

d. Siswa merespon sangat positif hasil pengembangan perangkat dan pelaksanaan pembelajaran inkuiri terbimbing dengan tugas proyek. Hal tersebut dapat dilihat 
dari rata-rata hasil analisis data respon siswa sebanyak 97,66\% siswa memberikan respon positif dengan kategori sangat kuat.

\section{KESIMPULAN}

Berdasasarkan hasil penelitian yang telah dilakukan dan telah diuraikan pada Bab $\mathrm{V}$, maka dapat disimpulkan bahwa perangkat pembelajaran berbasis inkuiri terbimbing dengan tugas proyek yang dikembangkan dinyatakan layak digunakan untuk ketuntasan hasil belajar siswa SMP pada materi sistem ekskresi.

\section{SARAN}

1. Pengembangan perangkat pembelajaran berbasis inkuiri terbimbing dengan tugas proyek dapat menuntaskan hasil belajar siswa sehingga perlu dikembangkan secara lebih luas pada materi pembelajaran IPA lainnya.

2. Persiapan dan pengelolaan waktu yang baik diperlukan dalam menerapkan pembelajaran berbasis inkuiri terbimbing dengan tugas proyek, agar pembelajaran berjalan dengan efektif dan efisien, sehingga siswa tidak mengalami kesulitan, karena pembelajaran berbasis inkuiri terbimbing dengan tugas proyek relatif menggunakan waktu yang cukup lama.

3. Perlunya sarana dan prasarana yang mendukung kegiatan praktikum yaitu alat dan bahan yang akan digunakan pada kegiatan praktikum, hendaknya dipersiapkan minimal satu minggu sebelum diadakan kegiatan pembelajaran.

\section{DAFTAR PUSTAKA}

Alberta. 2004. Focus Inquiry. A Teacher's Guide to Implemeting Inquiry- Based Learning. Edmonton Alberta. Canada.

Anderson, L.W. and Krathwol, D.R. 2001. A Taxonomy for Learning, Teaching and Assesing. Addison Wesley Longman. United States.

Arends, R. 2012. Learning to Teach Edisi Kesembilan Buku 1. Salemba Humanika. Jakarta.

Banchi., Heather., Bell Randy,. 2008. The many Levels of Inquiry, Inquiry Comes in Various Forms. Dalam Science and Children, diunduh pada tanggal 23 Februari 2016.

Basoeki, S. 1988. Anatomi dan Fisiologi Manusia. Depdikbud. Direktorat Jenderal Pendidikan Tinggi, P2LPTK. Jakarta.

Bilgin, I. 2009. The Effects Of Guided Inquiry Instruction Incorporating A Cooperative Learning Approach on University Students'achievement of Acid and Bases Concepts and Attitude Toward Guided Inquiry Instruction. Scientific Research and Essay. Vol. 4 (10), pp 1038-1046. 
Borich, G.D. 1994. Observation Skills for Effective Teaching. Mac Millan Publishing Company. New York.

Campbell. Reece. Urry. Cain. Wasserman. Minorsky. Jackson. 2012. Biologi. Edisi Kedelapan Jilid 2. Erlangga. Jakarta.

Carin, A. A. 1993. Teaching Modern Science. Macmillan Publishing Company. New York.

Dahar, R. W. 2011. Teori-Teori Belajar dan Pembelajaran. Erlangga. Jakarta.

Depdiknas. 2008. Panduan Pengembangan Silabus. Depdiknas Dirjen Pendidikan Dasar dan Menengah. Jakarta.

Depdiknas. (2008). Panduan Pengembangan Bahan Ajar. Jakarta. Direktorat PSMA.

Deta, U.A., Suparmi,. Widha, S. 2013. Pengaruh Metode Inkuiri Terbimbing dan Proyek, Kreativitas, Serta Keterampilan Proses Sains Terhadap Prestasi Hasil Belajar Siswa. Jurnal Pendidikan Fisika Indonesia. UNNES Semarang JPFI. ISSN: 16931246.

Dick, W., Carey, L., \& Carey, J.O. 2009. The Systematic Design of Instruction. $7^{\text {th }}$ Editions. Pearson Education Ltd. London.

Prastowo A. (2012). Panduan Kreatif Membuat Bahan Ajar Inovatif. Diva Press. yogjakarta

Prastowo, A. (2013). Pengembangan Bahan Ajar Tematik. Diva Press. Yogjakarta.

Ratumanan, Tanwey Gerson dan Laurens, Theresia. (2011). Penilaian Hasil Belajar pada Tingkat Satuan Pendidikan Edisi 2. Unesa University Press. Surabaya

Yager, R. E. (Ed.). (1992). International Council of Associations for Science Education. Boulevard Arlingtons. ICASE. North Washington.

Yu, Y., Tsai, C., Wu, L. (2013). "Effect of online procedural scaffolds and the tim ing of scaffolding provision on elementary Taiwanese Students' question-generation in a science class". Australasian Journal of Educational Technology. Ascilite. 29 (3). 